\title{
Identifying barriers to successful dairy cow transition management
}

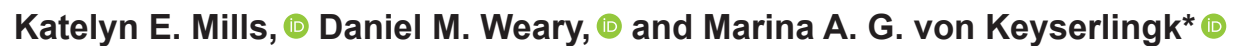 \\ Animal Welfare Program, Faculty of Land and Food Systems, University of British Columbia, 2357 Mall, Vancouver, BC, Canada V6T 1Z
}

\begin{abstract}
Many dairy cows become ill in the weeks after calving, a period when cows also experience numerous environmental and physiological changes. Most research on this transition period has focused on biological factors including nutrition, immunology, and physiology, but little work has examined sociological factors affecting how farmers care for their cows. The aim of the current study was to describe barriers preventing the adoption of more successful management practices. We used individual and group interviews, paired with photo elicitation, to understand the perspectives of farmers $(\mathrm{n}=11)$ and veterinarians $(\mathrm{n}=8)$ living and working in the lower Fraser Valley of British Columbia, Canada. Participants viewed transition period management as difficult. The lack of a single definition of the transition period emerged as one barrier to improvement; providing a clear and consistent definition for the transition period may be an important first step to improved practices on dairy farms. Participants also identified other barriers hindering improvement, including variation in both farmer attitude toward transition cow management and veterinarian involvement, stocking density of cows, and nutrition management. Barriers to improved practices varied by farm, suggesting that a tailored approach is required to make meaningful change.

Key words: animal welfare, extension, stakeholder engagement, qualitative method
\end{abstract}

\section{INTRODUCTION}

The transition period is generally defined in the academic and veterinary literature as 3 wk before to 3 wk after a cow gives birth to a calf (Grummer, 1995; Drackley, 1999; Mulligan and Doherty, 2008). During this period the cow experiences numerous environmental changes, including diet changes and regroupings, and physiological changes associated with parturition

Received December 31, 2018.

Accepted September 28, 2019.

*Corresponding author: nina@mail.ubc.ca and the onset of lactation (Grummer, 1995; Cook and Nordlund, 2004). Unfortunately, many cows become sick in the month after calving (LeBlanc, 2010). Researchers working in nutrition, immunology, physiology, and veterinary medicine have done the majority of the research targeted at reducing illness (Overton and Waldron, 2004; Mulligan et al., 2006). Recently, many studies have focused on the behavior of these animals and how it changes in response to illness (Proudfoot et al., 2009; Itle et al., 2015). Similarly, there has been an increase in literature targeted at practitioners on how best to improve transition period management practices (Atkinson, 2016).

Some work has surveyed management practices associated with the transition period. For example, Heuwieser et al. (2010) surveyed 429 dairy farms in Germany to better understand management practices for transition cows, including how often cows were monitored and whether they had a designated fresh pen. Robichaud et al. (2016) looked at calving management practices on Canadian farms and found that group calving was most common in freestall barns and that cows spent on average $14.5 \mathrm{~d}$ in the calving area. These previous survey data provide an understanding of what farmers do, but not why they do it. Qualitative methods such as interviews can be used to understand values, attitudes, or motivations of participants (Berkwits and Inui, 1998). To our knowledge, no stakeholder research has focused on the transition period from a qualitative perspective.

Understanding this problem from a new perspective may help to close the gap between research and practice, a problem not unique to transition cow management or indeed agriculture. Researchers working in public health (see review by Glasgow and Emmons, 2007) and social work (Pettus-Davis et al., 2011) have developed tools and strategies to help practitioners close the gap between research and practice. Focusing on agriculture, Peden et al. (2018) reviewed the literature on pig aggression and evidence of uptake of best practices in the industry (as measured by industry magazines and other gray literature); they attributed the minimal uptake of these practices to (1) the problem being viewed as low priority, (2) the perceived impracticality of new practices, (3) ineffective communication to the farm- 
ing community, and (4) economic factors. It is unclear what is causing this research-to-practice gap in transition period management.

One approach to the problem is to identify barriers preventing improvement. This approach has been used in other industries to understand barriers to adoption (for examples in the medical field, see reviews by Kruse et al., 2016 and Yusif et al., 2016). In agriculture, barriers to adoption of more sustainable practices have been identified as information dissemination, economics, social factors, farmers' characteristics, and infrastructure conditions (Rodriguez et al., 2008). This approach also has been used to help understand barriers to implementing environmentally friendly practices in the dairy supply chain (Ghadge et al., 2017) and at the farm level to understand barriers to reducing lameness on dairy farms (Leach et al., 2013); both studies employed surveys as the primary method of data collection. Turner et al. (2017) put forward a similar concept of "boundaries to change" in a study that explored beef and sheep farmers' approach to change. This concept "describe[s] the way management, infrastructure, land, enterprises, labour and debt factors can constrain change rather than acting as an obstacle or barrier to any change taking place" (Turner et al., 2017, p. 11). These authors go on to explain that some of these boundaries may be firm, making it unlikely for change to occur, whereas other boundaries are more flexible. The degree to which boundaries are firm or flexible also varied among individual farmers. From the existing literature, it is unknown what barriers or boundaries to improvement exist in transition period management.

The lower Fraser Valley region of British Columbia has a high density of dairy farms. This study sought to describe barriers to improved transition period management from the perspective of farmers and veterinarians in this region, using individual and group interviews paired with photo elicitation. Photo elicitation was used to add depth to interviews and to facilitate collaboration between the interviewer and participant as they discussed the meaning of the photo (Harper, 2002).

\section{MATERIALS AND METHODS}

This research was approved by the University of British Columbia's Behavioral Research Ethics Board (H17-00182).

\section{Participants}

This qualitative study used interviews with photo elicitation to understand the views of farmers $(\mathrm{n}=11$; 10 men and 1 woman) and veterinarians $(\mathrm{n}=8 ; 6$ men and 2 women). Purposive sampling (Given, 2008) was used to contact the 4 veterinary clinics in the region, with 3 clinics agreeing to participate. To recruit farmers, each veterinary clinic forwarded study information to their clients (i.e., chain-referral sampling; Penrod et al., 2003). In addition, farmers known to the authors through the dairy farm community were contacted. Farmers that participated in the study were owners, herd managers, or both, within the lower Fraser Valley region of British Columbia. All farmer participants had freestall facilities and milked on average 250 cows (range 80-500). Participants were recruited until saturation (i.e., the point at which new ideas were no longer heard; Guest et al., 2006) was reached in relation to the study objectives.

\section{Interviews}

Interviews were conducted by the lead author (Mills) as part of her $\mathrm{PhD}$ dissertation, working from a critical realist perspective (Guba and Lincoln, 1994). The lead author was trained in qualitative methods and had previous experience leading interviews and focus groups. Interviews were chosen as the primary method of data collection for this study to allow individual opinions to be collected without fear of judgment from colleagues or peers. A semi-structured interview guide was created and pilot tested with a separate group of veterinarians and farmers (see Supplemental Table S1 for interview guide, https://doi.org/10.3168/jds.2018-16231); these interviews were not included in the analyzed data because they were not practicing in the region of interest. A semi-structured interview guide was chosen to allow for the participants' responses to guide the direction of the conversation. The spirit of these question was adhered to, but wording was altered depending on context. Participants were contacted over the phone, email, or both, and were told the goals of the study. On the day of the interview, all participants signed a consent form before interviews began and were offered a copy of the consent form to keep for their records. Interviews were conducted between April and October 2017 and averaged $25 \mathrm{~min}$ in length (13-50 min range), not including warm-up questions (e.g., about their farm, business, and other small talk to make the participants comfortable with the interviewer, often provided during an impromptu farm tour). Warm-up questions were included to ensure that participants felt comfortable with the lead researcher. Veterinary interviews (8 individual interviews) all took place in the veterinarian's office. Due to unpredictable schedules of veterinarians, scheduled interviews were sometimes cut short due to emergency calls or client needs. Although the lead author used the 
time allotted to the best of their ability, this could be considered a limitation. Farmer interviews (6 individual interviews, 2 group interviews with 2 and 3 participants at their request and only when there was more than one decision maker on the farm) took place in the participant's home or barn. The location of the interview was the choice of the participant to ensure that they were in an environment where they were comfortable. Active listening techniques such as paraphrasing participants' words and reflecting back, revisiting earlier comments from participants for clarity, and revisiting inconsistencies in their stories or discussion were all used to help clarify participant perspectives throughout the interviews.

\section{Photo Elicitation}

Farmers and veterinarians were asked to take a photo of something on their own or a client's farm that they perceived as positive for transition cow welfare or something they were proud of in their transition program. The conversation surrounding the photo and the photos themselves were included for analysis. In some cases, farmers gave a tour of the farm and the lead author (Mills) took the photo of the area that the farmer indicated they were proud of (see Supplemental Figure S1 for examples of photos taken, https://doi.org/10.3168/ jds.2018-16231).

\section{Analysis}

All interviews were transcribed by a professional transcription service and compared with the audio recording for accuracy. Transcripts were provided to participants to ensure that their thoughts were expressed accurately. Transcripts and photos were coded by the first author (Mills) using NVivo (QSR International, Burlington, MA) qualitative data analysis software using open coding in which inductive codes were created from the data set (Marshall and Rossman, 2016). A codebook was then developed that grouped codes into larger themes (Macqueen et al., 1998). Using this codebook, the lead author and another trained researcher coded a subset of the interviews; any disagreements were discussed and the codebook was changed. New transcripts were coded by both researchers and this process repeated in an iterative way until agreement was reached and both researchers were satisfied with the final codebook. Once no further changes were made to the codebook, the lead author recoded all of the transcripts. Data were not analyzed separately by stakeholder group (i.e., farmers, veterinarians), but the quotes provided below are identified as from veterinarian or farmer participants (e.g., V1 and F1, respectively). Quotes are provided as examples from the data and were modified for length and clarity when needed.

\section{RESULTS}

The results of this study present the complexities of managing the transition period from the perspective of veterinarians and farmers in this study. Participants generally felt that transition management was going well and that the health of dairy cows was gradually improving. However, certain aspects of farm management emerged as barriers to improving transition management. Four themes that emerged (see Figure 1) were (1) definition of transition period and sources of information that aid in improvement, (2) farmer attitude toward health and welfare of transition cows, (3) identified limiting factors influencing transition management, and (4) veterinarian involvement in the transition period.

\section{Theme 1: Definition of Transition Period and Sources of Information that Aid Improvement}

Defining the Transition Period. Participants had varying definitions of "transition period." Veterinarians consistently perceived this time to be 3 wk before to 3 wk after calving. However, as one veterinarian explained, this definition has changed over time: "It used to be we'd talk about transition as being calving day, and then it got expanded to 21 days before calving ... then 21 days post-calving ... now, I would think of it even as the far-offs or the 45 to 60 days pre-calving through the fresh group calving, then 21 days following" (V1). For farmers, there was more variation in how the transition period was defined, and in many instances, participants defined it based on their management. For example, one participant defined transition as "two to three weeks pre-calving when they go into my closeup pen. I would do longer, but I'm a little tight on space. And they leave the fresh pen at four days fresh" (F1; see also Supplemental Figure S2, https://doi.org/10.3168/ jds.2018-16231). One participant defined this as any transition to a new group: "It's all the group changes in between. Moving them into the dry cows, they usually fight for a few days. Then moving them onto the pack, they usually ride around" (F11).

Sources of Information. Sources of information such as conferences, websites, and data from programs such as Dairy Comp (Valley Agricultural Software, Tulare, CA) were viewed as motivating management tools on farm. For example, farmers reported using milk pro- 
duction data to track production abnormalities (i.e., drop in milk) that could serve as an alert to monitor the cow more closely. Data were also used to track herd disease statistics over time, which were then discussed with the veterinarian during herd health visits.

Benchmarking, which helps farmers compare their performance with that of their peers, was generally seen as motivating, although some participants felt that could also be a barrier. For example, when discussing benchmarks performed by the veterinary clinic for clients one veterinarian explained, "There have been a couple of clients that I don't even show them their results, because I can't figure out how I'm going to use this in a positive way. So, I just don't show them" (V3).

Another important source of information identified was scientific research, and this was viewed as both a barrier and a motivator. Some participants incorporated research findings when making management or facility design decisions. However, other participants felt that inconsistencies between studies made these difficult to interpret. When describing an expansion to their facility one farmer stated, "We're trying to do it according to all these studies, but then we do it all, then another study comes out saying that was all wrong" (F2).

\section{Theme 2: Farmer Attitude Toward Health and Welfare of Transition Cows}

Participants discussed the importance of attitude toward transition cow management. For example, one veterinarian explained, "I think it's just the ones that do well are the ones that have that drive to excel and to do well. There's some farmers that always think, 'Well, that's good enough,' and that probably doesn't make a good farmer" (V3). Underlying these attitudes toward management was a sense of pride in taking care of their farm: "There's pride in the work. I have clients that they don't want to see a sick cow. Even if it costs them

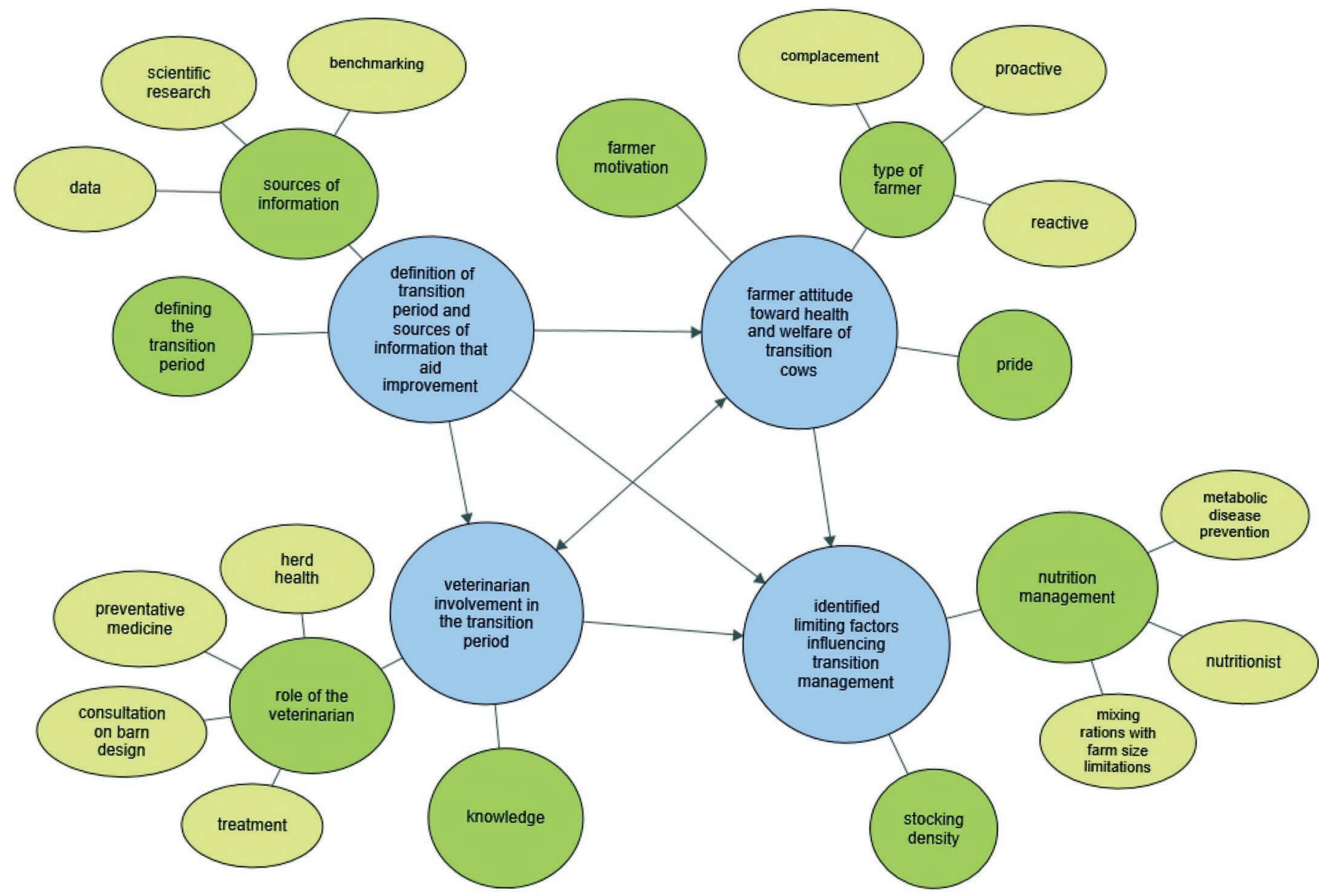

Figure 1. Thematic map of barriers to improved transition management with themes presented in blue and subsequent sub-themes presented in green. 
money or if it's less profitable, they're going to treat the herd better because they take pride in how the cow looks" (V1). Along with pride, the transfer of attitudes from one generation to the next was noticed by participants. For example, one veterinarian explained, "There is this group of young farmers that still have been-I shouldn't say brainwashed - but they learned it all from their fathers, but [others] have gone away, worked off the farm, a few of our young farmers have gone to New Zealand or Australia to work for a period of time so that gives them a chance to see and ... that gets them a chance to talk to other young farmers and ... put a different twist on what the previous generation did" (V8).

According to participants, transition period success or failure was largely dependent on style of management. Management styles that emerged from this study were proactive, complacent, and reactive and were dependent on the farmers' individual attitudes and personal characteristics.

The proactive management style included an element of long-term thinking as farmers were planning for the future or voicing what they hoped to achieve. For example, one participant explained, "We always try and keep on the cutting edge of things in terms of how to monitor our animals, and be more preventative as opposed to treating problems as they come" (F4). This theme was also echoed by a veterinarian, "Farms that are taken over by younger, more progressive generation, [are] thinking more and more to how do we prevent disease, not just fix problem stuff" (V4).

Complacent management reflected a degree of contentment with the current status of their transition cows and these farmers typically did not plan to make changes. In the words of one veterinarian, "There are some farmers that always think, 'Well, that's good enough' (V3). There was also the feeling of "it's not broke, don't fix it" (V6).

The reactive management style was one in which changes or decisions were made only once problems arose. For example, when describing monitoring of disease incidence, one farmer stated, "If there's a bunch of something all of a sudden, then we'll look at it. But, for the most part we don't actually look at it too much" (F11).

Underlying these management styles were the reasons that farmers have for making changes in their transition cow program. Veterinarians felt that understanding these reasons helped them communicate with their clients. For example, one respondent suggested that economic impact was the key factor to discuss with one of their clients: "Putting an economic spin on that, we can say to them, when we do this, this is the value we receive from it" (V7).

\section{Theme 3: Factors Influencing Transition Management}

Stocking Density. Farmer and veterinarian participants viewed stocking density during the transition period as a key aspect of transition cow management and this was often discussed in relation to the limitations of the facilities. Some participants refused to overstock their transition pen because they noticed detrimental effects on the cows. For example, one farm was proud of the fact that they housed all fresh cows at a stocking density of $70 \%$ for at least 2 wk before moving them into the main milking herd. The following interaction between 2 farmers illustrates how they viewed the value of understocking for the purpose of monitoring fresh cows:

F3: Most people don't [understock] because [they see this as] a waste of space. How many milk cows could you put [into the pen]?

F2: You could put 100 in there.

F3: Yeah, you're supposed to put 100 cows. Where we would put a maximum of 70 because we are understocking this part of the barn. Other guys [might say] "oh, it's a waste of space..." Look, I don't know how these guys do it because you see this cow, she calves, 3 to 4 days later she [is] taken to the herd. How are you going to look for her? How are you going to find her again?

In contrast, some farmers favored overstocking because they viewed this as a way to milk more cows. This was specifically related to increased quota allotments with 2 farmers stating the number of cows they have in a 75-cow pen:

F7: Eighty's too much, but I mean, with the quota and stuff, we've managed to-

F8: We're pretty crowded right now.

F7: It's crowded, but we-yeah, we-yeah, we-

F8: Well, I wouldn't say crowded. We're full. (Laughs)

F8: We're full. Yeah, they've given us allotments of quota this year. Like, $15 \%$ so far this year.

When discussing this extrinsic barrier, one veterinarian described perceived risks associated with this approach: "If a barn is full and now we want to make more milk, 
the poorly managed farms will try to do that by jamming a few more cows in there. Now they're crowded. You could argue you'll make a little bit more milk for short term, but then you're going to have really poor efficiency, because now ... the bottle neck will become cow comfort" (V1).

Farmers also had some disagreement on what was considered overstocked, particularly when looking at availability of different resources such as the feeding space or lying stalls per cow. For example, farmers from one farm viewed their pen as full, but not overstocked, despite providing insufficient feeding spaces for all cows to feed at once.

Nutrition Management. Nutrition management was viewed as one of the most important aspects of managing the transition period. Proper nutrition was viewed as an important preventative measure for avoiding transition period diseases such as ketosis. For example, one veterinarian stated, "If you've got your nutrition right-you still need to manage them properly - it's huge, because LDAs [left-displaced abomasum] and ketosis are really nutritional diseases" (V3). Similarly, participants attributed changes in health of transition cows to dietary problems and often sought the advice of their nutritionist or veterinarian to help solve this sort of problem.

Nutrition management was also viewed as a challenge for some farmers, including mixing specific rations for different periods. For example, as one veterinarian explained, "To make a ration right-let's say you're a small farm and you've got five close-up cows. Well, there is an ideal ration ... But if you have five cows, how can you make a ration that's just right just for those five cows? It might mean that you need some specific inventory, but what if you run out of that hay because of what the weather was doing last summer? It can be a real challenge on a small farm" (V1). This challenge was thought to result in some cows getting a diet that was deemed "too good for them" (F8; when discussing dry cows) or not good enough. Participants also felt that it was important both to create the correct ration and to ensure that the cows consumed this ration; the latter was thought to be affected by management practices and aspects of the cow's physical environment. For example, "If you are feeding a low energy, high straw ration and you don't have enough water space, then the cows will drop in intake, because they're thirsty. They need that water to get that straw and everything digested. So, if you don't have that, then you're going to affect your intakes. And if your intakes are low, your transition cow issues go up" (V5).

Nutritionist Involvement. Nutritionists were viewed as important stakeholders in transition management by both veterinarians and farmers. Farmers mentioned the value of contacting the nutritionist when problems arose. Participants felt that nutritionists were largely responsible for the success or failure of their transition cows. For example, "I'm not the kind of farmer who's going to have a nutritionist come, and sit down, and write me up a ration and then not follow it. I pay him to write me a ration, so I'm going to follow it, and then I'll hold him accountable for whatever is going to happen" (F4).

\section{Theme 4: Veterinarian Involvement in the Transition Period}

Veterinarian Involvement. Veterinarians were viewed as important advisors in transition management. Some participants discussed how the veterinarian was involved in changes made on farm. For example, "I lean on... my vet[erinarian] for pretty much everything that we do policy change wise. I don't go out and do anything without kind of conferring with [my veterinarian]. I just think it's important. If you're going to go ahead on your own, doing your own thing, then, you know, if it goes sideways you don't have anyone to back you up" (F5). The frequency of herd health visits varied among farms (ranging from every week to every $4 \mathrm{wk}$ ), but all participants reported that these visits were regularly scheduled. Herd health visits were the main time farmers discussed their transition cows with the veterinarian. Veterinarian involvement with transition cows included traditional veterinary services such as disease treatment, as well as advice on management and barn design. Some veterinarians in this study also described their shift in focus to preventative medicine and encouraged their clients to do the same.

Knowledge. Participants expressed normative claims about what should be done or what is considered best practice for transition cows; however, various limitations prevented farmers from providing optimal conditions for their transition cows. For example, one veterinarian (V4) stated, "I think for the most part, the farms do a really good job, or at least they know what they need to do to reduce these transition issues ... I think not everyone can [adopt] best practices. I think the ones that aren't doing best practices are aware of [this] and just accept their limitations."

Farmers valued their veterinarians' knowledge. For example, one farmer said, "They're educated, right? So, they have the opinion that's supposed to be a good opinion" (F2). In contrast, veterinarian participants often viewed farmer education as largely reflective of traditional knowledge of the farm. For example, one veterinarian felt that farmers "do things that their dad did. They do things that their neighbor did. Yeah, it's a lot of tradition" (V1). 


\section{DISCUSSION}

The results of this study show the complexities of managing the transition period from the perspective of veterinarians and farmers with many of the themes being interconnected. For example, farmer attitude toward transition management may influence veterinarian and nutritionist involvement. This underscores the complexity of this period and the importance of discussion between all parties involved. Additionally, how stakeholders discuss the transition period is important; farmer and veterinarian participants in this study defined the transition period differently, which could be a barrier to improvement. Ventura et al. (2016) identified ambiguity around the definition of animal welfare as a challenge for dairy and beef cattle veterinarians, possibly leading to inconsistent messaging to farmers. Confusion around definitions was also found in a study assessing Brazilian dairy stakeholder understanding of lameness (Olmos et al., 2018). Recognizing the difference in terminology used may provide an opportunity for veterinarians and farmers to engage on the issue, and thus better identify shared goals.

Some sources of information identified by both farmers and veterinarians were perceived to facilitate improvement in transition management, but in some cases, these could also act as barriers. For example, benchmarking was perceived as helpful by some participants but not others. Benchmarking has been done on several different aspects of dairy farming including efficiency of nutrient use (Mu et al., 2017) and health status of lactating dairy cows (Parker Gaddis et al., 2016). Sumner et al. (2018) found that farmers generally perceived benchmarking calf welfare as beneficial, as it allowed them to understand how well their animals were managed through peer comparison. By showing clients a benchmark report, veterinarians give autonomy to their client to make changes based on the information they receive.

The current study illustrated some disagreement about the application of scientific research. Some participants found research motivating, but others found it difficult to apply given conflicting results from different studies. Hansen and Greve (2015) found that human capital, defined in their study as years and level of farmer education, had a direct effect on farm performance as measured through productivity for Norwegian dairy farmers. Additionally, Vanclay (2004) explained that uptake of scientific knowledge is often done when it aligns with farmers' own knowledge and values (i.e., "science does not automatically have credibility and legitimacy"; Vanclay, 2004, p. 216). Previous research has noted difficulties in communicating scientific research to nonscientists, and in helping them make informed decisions (Treise and Weigold, 2002); lack of scientific literacy can be a barrier to science communication and training stakeholders in how to communicate scientific results more effectively is needed. Through knowledge mobilization activities (i.e., "all the activities and products created that help your research be useful and used"; Rowell, 2017, p. 334), transition cow research that has taken place for decades may help farmers with "real life" problems. Trusted advisors, such as the veterinarian, can help in communicating these scientific results to farmers.

Participants in this study discussed the importance of farmer attitude toward transition cow management. Understanding attitude toward management (e.g., as influenced by the type of farmer; Richens et al., 2016) can be important. Ritter et al. (2017) conducted a review on farmer adoption of management practices to prevent or control disease and found that understanding the farmer's mindset was important when attempting to motivate change. Many factors influence a farmer's decision-making, including personality, goals for the farm, and previous experience (Ritter et al., 2017). In the current study, veterinarians sometimes provided economic arguments when discussing changes with their clients. On the topic of biosecurity, Shortall et al. (2018) found that the capital investment (see Bourdieu, 1986) required to increase herd size increased the likelihood that farmers would listen to veterinary advice. However, other studies have found that economics may not be the primary consideration for farmers (Magalhães-Sant'Ana et al., 2017). Derks et al. (2013) found that veterinarians could not identify a farmer's goal after a herd health visit and were reluctant to ask farmers what their goals were. Similarly, Bard et al. (2017) found that farmers' motivation was assumed by veterinarians but not explicitly asked of them. While additional factors influence farmer decision-making, farmer-veterinarian communication may be a key factor to overcoming barriers to transition management and other issues on farm.

Factors thought to be associated with transition cow health included stocking density and nutrition. This is not surprising; many biological studies on transition cow management have focused on stocking density (e.g., Lobeck-Luchterhand et al., 2015) and nutrition (e.g., Loor et al., 2007). However, instances where participant farmers perceived an inability to change these factors may reflect them prioritizing other farm goals. For example, some farmers may place greater priority on increased milk shipments, and view having more animals in the pen as a way to achieve this goal. Identifying differences in priorities represents another opportunity for improved communication among stakeholders. In some cases, veterinarians and other advisors 
may also play a positive role in discussing longer-term risks associated with practices like overstocking. This is just one example of expanding the role of the veterinarian (van der Leek, 2015), with a focus on preventative medicine (Atkinson, 2016; Ruston et al., 2016), a point echoed by participants in this study.

Participants, both veterinarians and farmers, had a sense that veterinary involvement in the transition period could be improved. Veterinarians were involved with farms primarily through scheduled herd health visits that are known to be beneficial for cow health (Derks et al., 2014; Speksnijder et al., 2015). Duval et al. (2017) found that French farmers believed veterinarians would always have a role on dairy farms, particularly for acute health cases that the farmers are unable to address. However, Kristensen and Jakobsen (2011) argued that veterinarians should work toward a more collaborative approach with their clients based upon open dialogue and a shared understanding of the goals of the farm. Veterinarians are a trusted source of information (Alarcon et al., 2014) and so by working collaboratively with clients (as opposed to a more paternalistic approach sometimes used; Bard et al., 2017), it may be possible to find more effective management strategies. For example, van Dijk et al. (2017) conducted a study using participatory policy making with farmers in the United Kingdom. This producer-led initiative included dairy farmers and veterinarians conducting workshops to draft new policy on antimicrobial stewardship. Not only did these workshops provide tangible outcomes that could be applied on farm, participants also benefitted from the dialog among stakeholders (van Dijk et al., 2017). This model could be applied at the farm level, allowing farm staff, owners, and advisors such as nutritionists and veterinarians to collaboratively develop on-farm policy and practices.

Nutritionists, despite being considered an important stakeholder in successful transition management, appeared to have a limited relationship with the farmers from the perspective of participants in this study. This limited involvement is also reflected in the literature as, to our knowledge, no research has specifically assessed nutritionist perspectives on dairy cow transition management, or issues related to dairy farm management. We encourage new work on the perspective of nutritionists, given their importance in transition management and perhaps other challenges on dairy farms.

This study is, to our knowledge, the first to assess stakeholder views on the transition period, but it has several limitations. One of these is that the interviewer (Mills) is a PhD student in the Animal Welfare Program at the University of British Columbia, and is neither a dairy farmer nor a veterinarian, and thus was likely viewed as an outsider. This could also be viewed as an advantage, as participants may be more willing to explain things in detail to someone they view as an outsider. Additionally, the results need to be understood within the context of the specific region where the study was conducted. Results may differ for other farms and other regions. In particular, given the proximity of the University of British Columbia farm, participants likely had some experience with research. An advantage of this relationship was that it provided a platform of trust that allowed us to engage with participants and for them to voice opinions on the sometimes contentious issues we have described. Finally, farmers were recruited through their veterinarian and directly by the authors; we recognize the possibility of recruitment bias.

\section{CONCLUSIONS}

A clear and consistent definition of the transition period may help farmers and veterinarians make transition-related decisions. Increasing veterinarian and farmer communication and collaboration in making decisions may help achieve improvements in transition period management. Barriers vary by farm, so an individualized approach is required.

\section{ACKNOWLEDGMENTS}

We thank the participants for contributing to this study. We also thank Nadia Xenakis (University of British Columbia Animal Welfare Program, Vancouver, Canada) for help with data analysis, and colleagues within the University of British Columbia Animal Welfare Program for help and support throughout this study, especially to Katie Koralesky for commenting on an earlier draft of this manuscript. Katelyn Mills was supported by the Social Science and Humanities Research Council of Canada (SSHRC; Ottawa, ON, Canada) Doctoral Fellowship. This research was funded in part by the Hans Sigrist Foundation (University of Bern, Bern, Switzerland) through the Hans Sigrist Prize awarded to MvK and, in part, by generous donations made to the University of British Columbia Animal Welfare Program.

\section{REFERENCES}

Alarcon, P., B. Wieland, A. L. P. Mateus, and C. Dewberry. 2014. Pig farmers' perceptions, attitudes, influences and management of information in the decision-making process for disease control. Prev. Vet. Med. 116:223-242. https://doi.org/10.1016/j.prevetmed .2013.08.004.

Atkinson, O. 2016. Management of transition cows in dairy practice. In Pract. 38:229-240. https://doi.org/10.1136/inp.i1829.

Bard, A. M., D. C. J. Main, A. M. Haase, H. R. Whay, E. J. Roe, and K. K. Reyher. 2017. The future of veterinary communication: Partnership or persuasion? A qualitative investigation of veterinary 
communication in the pursuit of client behaviour change. PLoS One 12:e171380. https://doi.org/10.1371/journal.pone.0171380.

Berkwits, M., and T. S. Inui. 1998. Making use of qualitative research techniques. J. Gen. Intern. Med. 13:195-199.

Bourdieu, P. 1986. The forms of capital. Pages 241-258 in Handbook of Theory and Research for the Sociology of Education. J. Richardson, ed. Greenway, New York, NY.

Cook, N. B., and K. V. Nordlund. 2004. Behavioral needs of the transition cow and considerations for special needs facility design. Vet. Clin. North Am. Food Anim. Pract. 20:495-520.

Derks, M., T. Van Werven, H. Hogeveen, and W. D. J. Kremer. 2014 Associations between farmer participation in veterinary herd health management programs and farm performance. J. Dairy Sci. 97:1336-1347. https://doi.org/10.3168/jds.2013-6781.

Derks, M., B. Van Woudenbergh, M. Boender, W. Kremer, T. Van Werven, and H. Hogeveen. 2013. Veterinarian awareness of farmer goals and attitudes to herd health management in the Netherlands. Vet. J. 198:224-228. https://doi.org/10.1016/j.tvjl.2013.07 .018 .

Drackley, J. K. 1999. Biology of dairy cows during the transition period: The final frontier? J. Dairy Sci. 82:2259-2273. https://doi .org/10.3168/jds.S0022-0302(99)75474-3.

Duval, J. E., N. Bareille, C. Fourichon, A. Madouasse, and M. Vaarst. 2017. How can veterinarians be interesting partners for organic dairy farmers? French farmers' point of views. Prev. Vet. Med. 146:16-26. https://doi.org/10.1016/j.prevetmed.2017.07.013.

Ghadge, A., M. Kaklamanou, S. Choudhary, and M. Bourlakis. 2017. Implementing environmental practices within the Greek dairy supply chain: Drivers and barriers for SMEs. Ind. Manage. Data Syst. 117:1995-2014.

Given, L. M., ed. 2008. Purposive sampling. Pages 697-698 in The SAGE Encyclopedia of Qualitative Research Methods. Vol 2. L. M. Given, ed. SAGE Publications, Thousand Oaks, CA.

Glasgow, R. E., and K. M. Emmons. 2007. How can we increase translation of research into practice? Types of evidence needed. Annu. Rev. Public Health 28:413-433. https://doi.org/10.1146/annurev .publhealth.28.021406.144145.

Grummer, R. R. 1995. Impact of changes in organic nutrient metabolism feeding the transition dairy cow. J. Anim. Sci. 73:2820-2833.

Guba, E. G., and Y. S. Lincoln. 1994. Competing paradigms in qualitative research. Pages 105-117 in Handbook of Qualitative Research. N. K. Denzin and Y. S. Lincoln, ed. Sage, London, UK.

Guest, G., A. Bunce, and L. Johnson. 2006. How many interviews are enough? An experiment with data saturation and variability. Field Methods 18:59-82. https://doi.org/10.1177/1525822X05279903.

Hansen, B. G., and A. Greve. 2015. The role of human and social capital in dairy farming. Rural Soc. 24:154-176. https://doi.org/ 10.1080/10371656.2015.1060718.

Harper, D. 2002. Talking about pictures: A case for photo elicitation. Vis. Stud. 17:13-26. https://doi.org/10.1080/14725860220137345.

Heuwieser, W., M. Iwersen, J. Gossellin, and M. Drillich. 2010. Short communication: Survey of fresh cow management practices of dairy cattle on small and large commercial farms. J. Dairy Sci. 93:1065-1068. https://doi.org/10.3168/jds.2009-2783.

Itle, A. J., J. M. Huzzey, D. M. Weary, and M. A. G. von Keyserlingk. 2015. Clinical ketosis and standing behavior in transition cows. J. Dairy Sci. 98:128-134.

Kristensen, E., and E. B. Jakobsen. 2011. Challenging the myth of the irrational dairy farmer; Understanding decision-making related to herd health. N. Z. Vet. J. 59:1-7.

Kruse, C. S., C. Kristof, B. Jones, and E. Mitchell. 2016. Barriers to electronic health record adoption: A systematic literature review. J. Med. Syst. 40:252. https://doi.org/10.1007/s10916-016-0628-9.

Leach, K. A., E. S. Paul, H. R. Whay, Z. E. Barker, C. M. Maggs, A. K. Sedgwick, and D. C. J. Main. 2013. Reducing lameness in dairy herds - Overcoming some barriers. Res. Vet. Sci. 94:820-825. https://doi.org/10.1016/j.rvsc.2012.10.005.

LeBlanc, S. J. 2010. Monitoring metabolic health of dairy cattle in the transition period. J. Reprod. Dev. 56:S29-S35. https://doi.org/10 $.1262 /$ jrd.1056s29.
Lobeck-Luchterhand, K. M., P. R. B. Silva, R. C. Chebel, and M. I. Endres. 2015. Effect of stocking density on social, feeding, and lying behavior of prepartum dairy animals. J. Dairy Sci. 98:240-249. https://doi.org/10.3168/jds.2014-8492.

Loor, J. J., R. E. Everts, M. Bionaz, H. M. Dann, D. E. Morin, R. Oliveira, S. L. Rodriguez-Zas, J. K. Drackley, and H. A. Lewin. 2007. Nutrition-induced ketosis alters metabolic and signaling gene networks in liver of periparturient dairy cows. Physiol. Genomics 32:105-116. https://doi.org/10.1152/physiolgenomics.00188.2007.

Macqueen, K. M., E. Mclellan, K. Kay, and B. Milstein. 1998. Codebook development for team-based qualitative analysis. Cult. Anthropol. Methods 10:31-36.

Magalhães-Sant'Ana, M., S. J. More, D. B. Morton, and A. J. Hanlon. 2017. Challenges facing the veterinary profession in Ireland: 1. Clinical veterinary services. Ir. Vet. J. 70:17. https://doi.org/10 $.1186 / \mathrm{s} 13620-017-0096-7$.

Marshall, C., and G. B. Rossman. 2016. Designing Qualitative Research. 6th ed. SAGE Publications, Thousand Oaks, CA.

Mu, W., E. A. Groen, C. E. Van Middelaar, E. A. M. Bokkers, S. Hennart, D. Stilmant, and I. J. M. De Boer. 2017. Benchmarking nutrient use efficiency of dairy farms: The effect of epistemic uncertainty. Agric. Syst. 156:25-33. https://doi.org/10.1016/j.agsy .2017.04.001.

Mulligan, F. J., and M. L. Doherty. 2008. Production diseases of the transition cow. Vet. J. 176:3-9. https://doi.org/10.1016/j.tvjl.2007 .12 .018 .

Mulligan, F. J., L. O. Grady, D. A. Rice, and M. L. Doherty. 2006. A herd health approach to dairy cow nutrition and production diseases of the transition cow. Anim. Reprod. Sci. 96:331-353. https: //doi.org/10.1016/j.anireprosci.2006.08.011.

Olmos, G., J. A. Bran, M. A. G. Von Keyserlingk, and M. J. Hötzel. 2018. Lameness on Brazilian pasture based dairies - Part 2: Conversations with farmers and dairy consultants. Prev. Vet. Med. 157:115-124. https://doi.org/10.1016/j.prevetmed.2018.06.009.

Overton, T. R., and M. R. Waldron. 2004. Nutritional management of transition dairy cows: Strategies to optimize metabolic health. J. Dairy Sci. 87:E105-E119. https://doi.org/10.3168/jds.S0022 -0302(04)70066-1.

Parker Gaddis, K. L., J. B. Cole, J. S. Clay, and C. Maltecca. 2016. Benchmarking dairy herd health status using routinely recorded herd summary data. J. Dairy Sci. 99:1298-1314. https://doi.org/ 10.3168/jds.2015-9840.

Peden, R. S. E., S. P. Turner, L. A. Boyle, and I. Camerlink. 2018. The translation of animal welfare research into practice: The case of mixing aggression between pigs. Appl. Anim. Behav. Sci. 204:1-9. https://doi.org/10.1016/j.applanim.2018.03.003.

Penrod, J., D. B. Preston, R. E. Cain, and M. T. Starks. 2003. A discussion of chain referral as a method of sampling hard-to-reach populations. J. Transcult. Nurs. 14:100-107. https://doi.org/10 $.1177 / 1043659602250614$.

Pettus-Davis, C., M. D. Grady, G. S. Cuddeback, and A. Scheyett. 2011. A practitioner's guide to sampling in the age of evidencebased practice: Translation of research into practice. Clin. Soc. Work J. 39:379-389.

Proudfoot, K. L., D. M. Veira, D. M. Weary, and M. A. G. von Keyserlingk. 2009. Competition at the feed bunk changes the feeding, standing, and social behavior of transition dairy cows. J. Dairy Sci. 92:3116-3123. https://doi.org/10.3168/jds.2008-1718.

Richens, I. F., P. Hobson-West, M. L. Brennan, Z. Hood, J. Kaler, M. Green, N. Wright, and W. Wapenaar. 2016. Factors influencing veterinary surgeons' decision-making about dairy cattle vaccination. Vet. Rec. 179:410. https://doi.org/10.1136/vr.103822.

Ritter, C., J. Jansen, S. Roche, D. F. Kelton, C. L. Adams, K. Orsel, R. J. Erskine, G. Benedictus, T. J. G. M. Lam, and H. W. Barkema. 2017. Invited review: Determinants of farmers' adoption of management-based strategies for infectious disease prevention and control. J. Dairy Sci. 100:3329-3347. https://doi.org/10.3168/ jds.2016-11977.

Robichaud, M. V., A. M. de Passillé, D. L. Pearl, S. J. Leblanc, S. M. Godden, and D. Pellerin. 2016. Calving management practices 
on Canadian dairy farms: Prevalence of practices. J. Dairy Sci. 99:2391-2404. https://doi.org/10.3168/jds.2015-9641.

Rodriguez, J. M., J. J. Molnar, R. A. Fazio, E. Sydnor, and M. J. Lowe. 2008. Barriers to adoption of sustainable agriculture practices: Change agent perspectives. Renew. Agric. Food Syst. 24:60-71. https://doi.org/10.1017/S1742170508002421.

Rowell, L. 2017. Knowledge mobilization and action research in global contexts: Towards a comparative orientation. Educ. Res. 25:333336.

Ruston, A., O. Shortall, M. Green, M. Brennan, W. Wapenaar, and J. Kaler. 2016. Challenges facing the farm animal veterinary profession in England: A qualitative study of veterinarians' perceptions and responses. Prev. Vet. Med. 127:84-93. https://doi.org/ 10.1016/j.prevetmed.2016.03.008.

Shortall, O., L. Sutherland, A. Ruston, and J. Kaler. 2018. True cowmen and commercial farmers: Exploring vets' and dairy farmers' contrasting views of 'good farming' in relation to biosecurity. Sociol. Ruralis 58:583-603. https://doi.org/10.1111/soru.12205.

Speksnijder, D. C., A. D. C. Jaarsma, A. C. van der Gugten, T. J. M. Verheij, and J. A. Wagenaar. 2015. Determinants associated with veterinary antimicrobial prescribing in farm animal in the Netherlands: A qualitative study. Zoonoses Public Health 62:39-51.

Sumner, C. L., M. A. G. von Keyserlingk, and D. M. Weary. 2018. How benchmarking motivates farmers to improve dairy calf management. J. Dairy Sci. 101:3323-3333. https://doi.org/10.3168/jds .2017-13596.

Treise, D., and M. F. Weigold. 2002. Advancing science communication. Sci. Commun. 23:310-322.
Turner, L., R. Wilkinson, and S. Kilpatrick. 2017. Boundaries to change: Insights into the change process of beef and sheep farmers. Rur. Exten. Innov. Syst. J. 13:9-18.

van der Leek, M. L. 2015. Beyond traditional dairy veterinary services: "It's not just about the cows! J. S. Afr. Vet. Assoc. 86:1-10.

van Dijk, L., A. Hayton, D. C. J. Main, A. Booth, A. King, D. C. Barrett, and H. J. Buller. 2017. Participatory policy making by dairy producers to reduce anti-microbial use on farms. Zoonoses Public Health 64:476-484. https://doi.org/10.1111/zph.12329.

Vanclay, F. 2004. Social principles for agricultural extension to assist in the promotion of natural resource management. Aust. J. Exp. 44:213-222.

Ventura, B. A., D. M. Weary, A. S. Giovanetti, and M. A. G. von Keyserlingk. 2016. Veterinary perspectives on cattle welfare challenges and solutions. Livest. Sci. 193:95-102. https://doi.org/10.1016/j .livsci.2016.10.004.

Yusif, S., J. Soar, and A. Hafeez-Baig. 2016. Older people, assistive technologies and the barriers to adoption: A systematic review. Int. J. Med. Inform. 94:112-116.

\section{ORCIDS}

Katelyn E. Mills @ https://orcid.org/0000-0001-7296-9214

Daniel M. Weary ㄴ https://orcid.org/0000-0002-0917-3982

Marina A. G. von Keyserlingk () https://orcid.org/0000-0002-1427 $-3152$ 